\title{
A novel surgical approach for the management of giant invasive prolactinoma compressing the brainstem
}

\author{
Niki Margari, Jonathan Pollock ${ }^{1}$ and Nemanja Stojanovic ${ }^{2}$ \\ Department of Endocrinology and Diabetes, Royal London Hospital, Barts Health NHS Trust, London, UK \\ Departments of ${ }^{1}$ Neurosurgery ${ }^{2}$ Endocrinology and Diabetes, Queens Hospital, Barking Havering and Redbridge \\ University Hospitals NHS Trust, Romford, Essex, UK
}

Correspondence

should be addressed

to N Margari

Email

margniki@gmail.com

\section{Summary}

Prolactinomas constitute the largest subsection of all secretory pituitary adenomas. Most are microprolactinomas and are satisfactorily treated by medical management alone. Giant prolactinomas, measuring more than $4 \mathrm{~cm}$ in diameter, are rare and usually occur more commonly in men. Macroprolatinomas tend to present with symptoms of mass effect rather than those of hyperprolactinaemia. Dopamine agonists (DA) are the treatment of choice for all prolactinomas. Surgery is usually reserved for DA resistance or if vision is threatened by the mass effects of the tumour. We describe the case of a 52 year-old woman with a giant invasive prolactinoma who required multiple surgical procedures as well as medical management with DA. One of the surgical interventions required a posterior approach via the trans cranial sub occipital transtentorial approach, a surgical technique that has not been previously described in the medical literature for this indication. The giant prolactinoma was reduced significantly with the above approach and patient symptoms from the compressing effects of the tumour were resolved. This case highlights the importance of a multidisciplinary approach to the management of such patients who present with florid neurological sequelae secondary to pressure effects. Although this presentation is uncommon, surgery via a sub occipital transtentorial approach may be considered the treatment of choice in suitable patients with giant invasive prolactinomas compressing the brainstem.

\section{Learning points:}

- Giant prolactinomas present with symptoms of mass effect or those of hyperprolactinaemia.

- Interpretation of the pituitary profile is crucial to guide further investigations and management.

- Treatment of giant invasive prolactinomas may involve a combination of medical management and multiple surgical interventions.

- Treatment with DA may cause pituitary haemorrhage or infarction in patients with these tumours.

- A sub occipital transtetorial approach may be considered the treatment of choice in invasive prolactinomas compressing the brainstem.

- Multidisciplinary approach of such patients is fundamental for a better outcome.

\section{Background}

We describe the case of a female patient who presented with ophthalmoplegia and subsequent pituitary profile and her image revealed a giant invasive prolactinoma compressing the brainstem. It was initially managed with dopamine agonists (DA) but on-going life-threatening neurological symptoms required urgent surgical intervention to release the pressure effects. This presentation is 
uncommon and several attempts of tumour debulking were required to protect vital structures.

A novel surgical approach in pituitary surgery via a sub occipital transtetorial route was followed which has not been previously described in the medical literature for this indication but may be considered as the treatment of choice in suitable patients.

\section{Case presentation}

A 52 year-old woman with a longstanding history of hypothyroidism on thyroxine replacement was referred to the ophthalmology clinic with suspected thyroid eye disease. She had a six-month history of feeling generally unwell and proptosis of the left eye with reduced vision. On examination she had left sided proptosis and ophthalmoplegia. Visual acuity in the left eye was Snellen 1/60 (LogMAR chart 1.3). Fundoscopy revealed bilaterally pale discs.

She had become amenorrhoeic at the age of 42 , which was attributed to menopause. Hypothyroidism was diagnosed three years before presentation, for which she was taking L-thyroxine $50 \mu \mathrm{g}$ once daily. She was on no other regular medication.

\section{Investigation}

Thyroid function tests revealed a thyroid-stimulating hormone (TSH) level of $4.2 \mathrm{mU} / 1$ (range 0.5-5.5) and free thyroxine (free $\mathrm{T}_{4}$ ) of $6.7 \mathrm{pmol} / \mathrm{l}$ (range 10-19.8). Pituitary function tests were requested urgently as TSH was disproportionately low relative to free $T_{4}$. These were in keeping with hypopituitarism (Table 1), with prolactin grossly elevated at >500 $000 \mathrm{IU} / \mathrm{l}$ (normal range 38-430). The patient did not report any galactorrhoea.

Imaging demonstrated a large destructive sellar mass $>6 \mathrm{~cm}$ in diameter compressing multiple compartments at the skull base (Fig. 1). The tumor was compressing the brainstem and also extending into the left parasellar region to encase the left carotid artery (Fig. 2A). It also extended upwards to compress the optic chiasm and

Table 1 Pituitary profile at presentation.

Prolactin
Luteinising hormone
Follicle stimulating
hormone
0900 h cortisol
Insulin-like growth
factor 1

$>500000 \mathrm{IU} / \mathrm{l}$ (normal range: 38-430)

$<0.2 \mathrm{IU} / \mathrm{I}$

$<0.2 \mathrm{IU} / \mathrm{I}$

$87 \mathrm{nmol} / \mathrm{l}$ (normal range: 171-618) $3.9 \mathrm{nmol} / /$ (normal range 9-40)

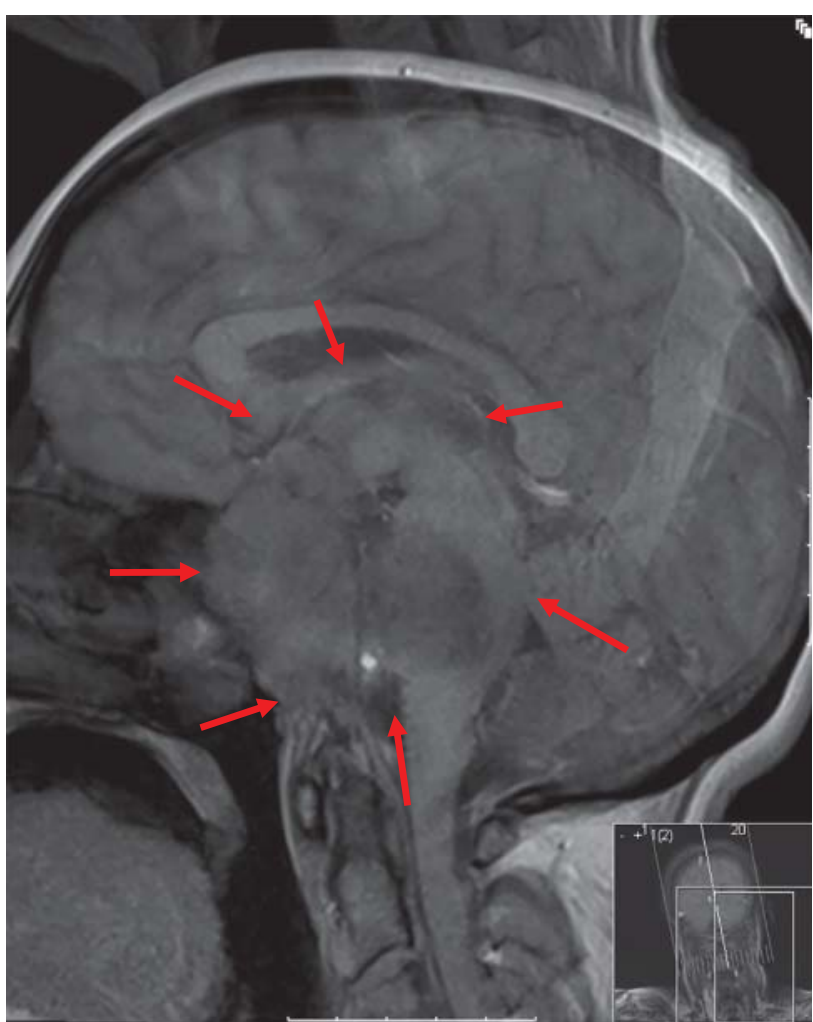

Figure 1

A giant prolactinoma $>6 \mathrm{~cm}$ in diameter (red arrows), involving the central skull base and compressing the brain stem.

invade the left orbit along the superior oblique muscle and the optic nerve (Fig. 2B).

\section{Treatment}

The available treatment options were discussed with the patient and she declined surgery. She was commenced on cabergoline and a replacement dose of hydrocortisone. A week later, she collapsed on the ward with a Glasgow Coma Scale of 7. An urgent computed tomography scan of the brain suggested minor hemorrhage within the tumor and acute hydrocephalus, which required emergency transsphenoidal debulking and insertion of external ventricular drains that were removed five days after the operation. This was done without complications. The posterior portion of the tumor was not treated operatively at this stage in the expectation of future shrinkage with Cabergoline therapy. Three weeks later the prolactin had fallen to $1369 \mathrm{IU} / \mathrm{l}$. She required prolonged neurorehabilitation but made good progress and was discharged home. On discharge the prolactin was $721 \mathrm{IU} / \mathrm{l}$.

Three months later she presented again with sudden onset of tetra paresis, dyspnea, slurred speech and pooling 


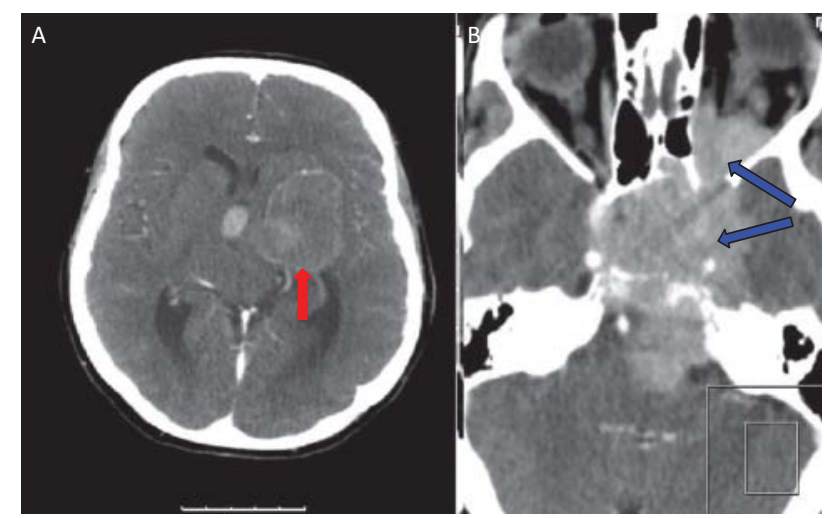

Figure 2

(A and B) A pituitary computed tomography scan reveals the extent of the skull-base tumor involving the sella, left striatum, posterior fossa ( $\mathrm{A}$; red arrow) and invading the left orbit (B; blue arrows).

of saliva within the mouth. Imaging showed evidence of tumor apoplexy within the portion of tumor adjacent to the brainstem where there was now increased mass effect causing significant compression of the brainstem (Fig. 3). Urgent debulking of the posterior portion of the tumor was indicated. This was done via a posterior approach via the sub occipital transtentorial route to safely access the large posterior fossa component of the tumor.

\section{Outcome and follow-up}

Recovery was slow but uncomplicated. Treatment with Cabergoline was continued throughout. Imaging conducted six months later demonstrated a further decrease in the size of the tumor.

The patient remained on Cabergoline $1 \mathrm{mg}$ twice per week for a year after the initial presentation. At that time deterioration in visual acuity was noticed in the left eye, which was a result of further tumor expansion in the orbit. The dose of Cabergoline was increased to $1 \mathrm{mg}$ daily with visual acuity returning to the baseline as a result (Fig. 4). Unfortunately the patient developed severe pneumonia and respiratory failure that needed tracheostomy. She did recover enough to be discharged home with a tracheostomy in situ. However, the patient died of presumed aspiration pneumonia at home six months after discharge and three years after the diagnosis of giant invasive prolactinoma.

\section{Discussion}

We describe a case of giant invasive prolactinoma where surgery via the sub occipital transtentorial approach was used to relieve the life-threatening pressure-dependent neurological symptoms caused by tumor apoplexy. Even though the common surgical technique for these tumors is the transphenoidal surgery, this surgical approach was selected as the preferred approach to this complex lesion and, to the best of our knowledge, has not been used previously in this setting.

Prolactinomas remain the most common of all secretory pituitary tumors and pharmacotherapy is usually successful (1) (2). DA remain first-line therapy for the majority of patients and surgery has been reserved predominantly for patients with DA resistance or intolerance (1) (2) (3). Several cases of pituitary apoplexy have been described in patients with prolactinomas after starting DA (4) which is thought to be the result of DA inhibition of the proliferation of both normal and neoplastic cells by inducing cell cycle arrest or apoptosis (5). A higher incidence of macroprolactinomas has been reported in men (6) (7). Men are also more likely to suffer from giant invasive prolactinoma, a more aggressive form of the disease, which is potentially life threatening (6) (7) (8). Prolactinomas larger than $5 \mathrm{~cm}$ are rare (1) (2), but may require surgery to relieve pressure on vital structures. Transsphenoidal surgery remains the procedure of choice for the vast majority of smaller pituitary tumors confined to the parasellar region including both micro- and macroprolactinomas.

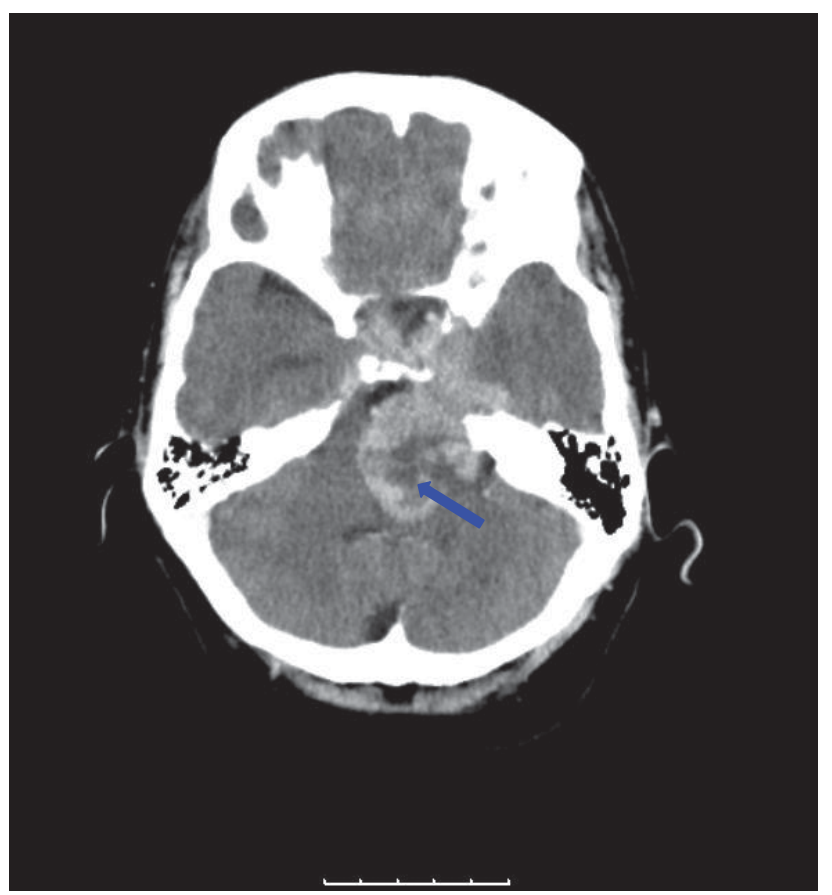

Figure 3

A computed tomography brain scan demonstrating bleeding into the tumor secondary to pituitary apoplexy (blue arrow). 


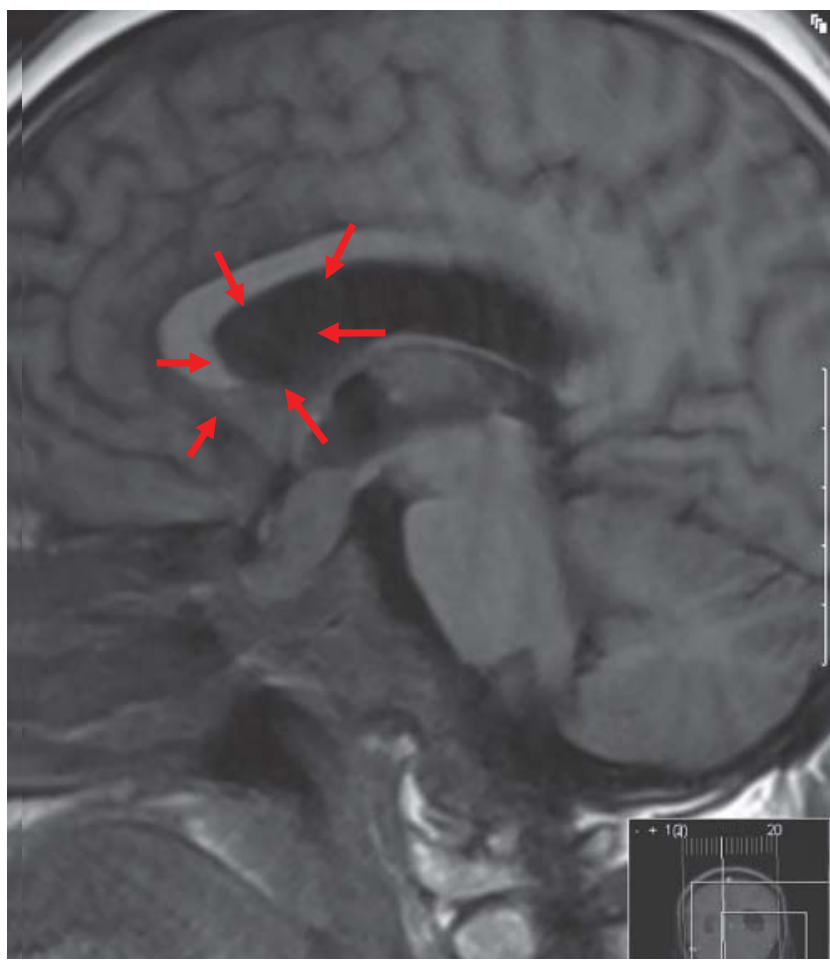

Figure 4

Pituitary magnetic resonance imaging taken after surgery and dopamine agonist therapy revealing significant reduction in tumor size (red arrows).

Despite recent guidelines for the treatment of prolactinomas (1) (2), the experience in management of giant invasive prolactinomas simultaneously affecting the orbit (10), skull base, and optic chiasm and compromising the rhombencephalic structures remains sparse. This case highlights the importance of a multidisciplinary approach to the management of such patients who present with florid neurological sequelae secondary to pressure effects (9). Although this presentation is uncommon, surgery via a sub occipital transtentorial approach may be considered the treatment of choice in suitable patients with giant invasive prolactinoma compressing the brainstem.

\section{Declaration of interest}

The authors declare that there is no conflict of interest that could be perceived as prejudicing the impartiality of the research reported.

\section{Funding}

This research did not receive any specific grant from any funding agency in the public, commercial or not-for-profit sector.

\section{Patient consent}

The patient is deceased.

Author contribution statement

The authors have contributed equally to the writing of the case report.

\section{References}

1 Casanueva FF, Molitch ME, Schlechte JA, Abs R, Bonert V, Bronstein MD, Brue T, Cappabianca P, Colao A, Fahlbusch R et al. 2006 Guidelines of the Pituitary Society for the diagnosis and management of prolactinomas. Clinical Endocrinology 65 265-273. (doi:10.1111/j.1365-2265.2006. 02562.x)

2 Melmed S, Casanueva F, Hoffman AR, Kleinberg DL, Montori VM, Schlechte JA \& Wass JA 2011 Diagnosis and treatment of hyperprolactinemia: an Endocrine Society Clinical Practice Guideline. Journal of Clinical Endocrinology and Metabolism 96 273-288. (doi:10.1210/jc. 2010-1692)

3 Gillam MP, Molitch ME, Lombardi G \& Colao A 2006 Advances in the treatment of prolactinomas. Endocrinology Reviews 27 485-534. (doi:10.1210/er.2005-9998)

4 Chng E \& Dalan R 2013 Pituitary apoplexy associated with cabergoline therapy. Journal of Clinical Neuroscience 20 1637-1643. (doi:10.1016/j. jocn.2013.02.027)

5 Zatelli M, Ambrosio M, Bondanelli M \& Uberti E 2007 Control of pituitary adenoma cell proliferation by somatostatin analogs, dopamine agonists and novel chimeric compounds. European Journal of Endocrinology 156 S29-S35. (doi:10.1530/eje.1.02352)

6 Delgrange E, Trouillas J, Maiter D, Donckier J \& Tourniaire J 1997 Sex-related difference in the growth of prolactinomas: a clinical and proliferation marker study. Journal of Clinical Endocrinology and Metabolism 82 2102-2107.

7 Shimon I, Benbassat C \& Hadani M 2007 Effectiveness of long-term cabergoline treatment for giant prolactinoma: study of 12 men. European Journal of Endocrinology 156 225-231. (doi:10.1530/EJE-060646)

8 Sharif DA, Nkonge FM, Chawda S, Benjamin J \& Stojanović ND 2010 Cystic degeneration of macroprolactinoma on long-term cabergoline. Journal of Clinical Endocrinology and Metabolism 95 3593-3594. (doi:10.1210/jc.2010-0900)

9 Davis JR, Sheppard MC \& Heath DA 1990 Giant invasive prolactinoma: a case report and review of nine further cases. QJM 74 227-238.

10 Harzallah F, Harzallah L, Ben Brahim A, Mekaouer A \& Slimane H 2009 Macroprolactinoma revealed by an exophthalmos. French Journal of Ophthalmology 32 133e1-133e3. (doi:10.1016/j.jfo.2008.12.005)

Received in final form 16 November 2015

Accepted 2 December 2015 